\title{
0 Papel das Instituições Educativas no Processo de Regeneração Social de Menores Delinquentes na Belém Republicana (1890-1910)
}

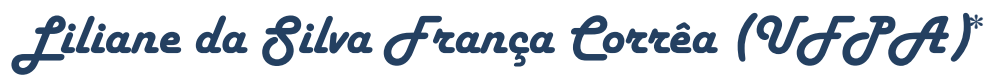

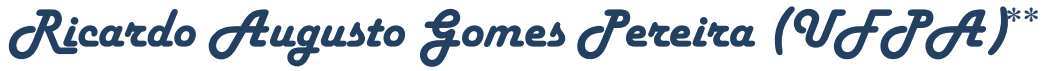 \\ Atriana flisa de Alencar Macedo (VみみA)****
}

\section{RESUMO}

Objetiva-se analisar o papel das Instituições Educativas no processo de regeneração social de menores delinquentes em Belém do Pará no período republicano, a partir dos dados da dissertação "A Infância em Processos Judiciais em Belém do Pará: da criminalidade aos discursos jurídico-assistencialistas para a educação do menor desvalido (1890-1930)". Descreve a constituição da infância brasileira, a relação da infância paraense com a criminalidade e as práticas educativas de instituições educativas de destaque nesse âmbito, como: o Instituto de Educandos Artífices Paraense e a Companhia de Aprendizes Marinheiros, apresentando 0 pensamento republicano paraense sobre a proposta

\footnotetext{
*Mestra em Educação pelo Programa de Pós-Graduação em Educação da Universidade Federal do Pará (PPGED/ICED/UFPA). Belém/Pará/Brasil. E-mail: lilafrcs@yahoo.com.br

${ }^{* *}$ Mestre em Desenvolvimento Regional (UNITAU). Mestre em Educação pelo Programa de PósGraduação em Educação (PPGED/ICED/UFPA). Belém/Pará/Brasil. E-mail: pereiraric19@ @mail.com

${ }^{* * *}$ Mestra em Psicologia pelo Programa de Pós-Graduação em Psicologia (PPGP/IFCH/UFPA). Belém/Pará/Brasil. E-mail: Drica_macedo@yahoo.com.br
} 
educacional oferecida aos menores delinquentes, conforme o código penal de 1890.

Palavras-chave: Infância. Delinquência Juvenil. Instituições Educativas.

\section{ABSTRACT}

This article aims to analyze the role of educational institutions in the process of social regeneration of juvenile delinquents in Belém do Pará during the republican period, based on data from the dissertation "Childhood in Judicial Processes in Belém do Pará: from criminality to legal and assistance discourses for education of the underprivileged minor (1890-1930)". It describes the constitution of Brazilian childhood, the relation of the children of Pará with the crime and the educational practices of prominent educational institutions in this field, such: as the Instituto de Educandos Artífices Paraenses and the Companhia de Aprendizes Marinheiros, presenting the republican thinking of Pará on the educational proposal offered to juvenile delinquents, according to the Penal Code of 1890.

Keywords:Childhood. Juvenile Delinquency. Educational Institutions.

\section{INTRODUÇÃO}

Sabe-se que sobre a historiografia da infância desvalida paraense muito ainda há para ser investigado. A compreensão que se tem da realidade socioeducativa de crianças e adolescentes envolvidos com a criminalidade hoje muito tem a dizer de sua constituição no passado. Acredita-se que a delinquência infanto-juvenil é uma mazela contemporânea, com raízes no período republicano. Nesse sentido, Corrêa (2017) destaca que, nos finais do século XIX, a cidade de Belém do Pará ficou marcada pelas transformações provocadas pela primeira república, em decorrência da Belle Époque e da comercialização da borracha, parte do processo de modernização da cidade, contribuindo

@rquivo Brasileiro de Educação, Belo Horizonte, v. 6, n. 14, mai-ago, 2018. 
para o aumento da criminalidade de menores.

Historicamente, a infância desvalida foi abandonada à própria sorte. Descaso, violência, abandono e trabalho infantil fizeram parte do cotidiano das crianças brasileiras desde o processo civilizatório. Tais atitudes eram consideradas normais, visto que a concepção de infância, no Brasil, não era diferente da de outros países e que, para algumas sociedades, sequer existiu até o século XII (CORRÊA, 2017, p. 40). Verificou-se que a aparição da infância como fase da vida que demanda cuidados e proteção ocorrev em torno dos séculos XIII e XIV, mas, os sinais de sua evolução só se tornaram evidentes no continente europeu nos séculos XVI e XVII (CORDEIRO; COELHO, 2006, p. 884). Segundo Sabino (2012), no Brasil colonial/imperial, a condição da criança foi definida de acordo com sua classe social e gênero.

A partir da República, o lema das autoridades brasileiras era salvar a criança pobre e desvalida, pois era vista como o "futuro da nação". Segundo Corrêa (2017), nesse período, o país vivenciou o processo de inserção de menores desfavorecidos e desocupados nas relações de trabalho e no convívio social, segundo "os novos padrões de convívio impostos pela modernidade, que eram estabelecidos e permeados pela industrialização, urbanização e crescente pauperização das camadas populares" (SANTOS, 1999, p. 211).

Não obstante, Belém do Pará passou por mudanças com o projeto de Antônio Lemos' que tornou a cidade um lugar seguro e civilizado para uma classe social em ascensão, utilizando, para isso,

\footnotetext{
${ }^{1}$ Antonio José Lemos (1843-1913) foi considerado o maior Administrador Municipal dos últimos tempos e o mais poderoso e recorrente político da Amazônia. Chegou a Belém como soldado da Marinha e começou a vida política no Partido Republicano, do qual foi secretário. A urbanização da cidade, projetada por ele nos finais do século XIX e início do XX, é recordada pela população como um período próspero, com delimitação do espaço urbano e definição dos direitos e deveres dos cidadãos, dando à cidade ares europeus, com avenidas, praças e arborização, incineração de lixo e limpeza urbana. Instituiu o liceu, que hoje corresponde ao ensino médio ou profissionalizante. Não pertencia a família tradicional e não tinha curso superior, mas, impôs-se como o político que representou a classe dominante do látex, cercado de intelectuais que o ajudaram na operacionalização do projeto da cidade, ofuscando o atraso e a incivilidade (MONTENEGRO, 2010).
}

@rquivo Brasileiro de Educação, Belo Horizonte, v. 6, n. 14, mai-ago, 2018. 
formas de combate à delinquência de menores, pensando-se a educação como proposta para sanar esse problema (CORRÊA, 2017). Corrêa (2017, p. 16) esclarece que:

Essa proposta se fomentou em um modelo de educação voltado para o trabalho, cuja importância desvelava a compreensão da aliança firmada entre Justiça e Assistência no que diz respeito à Educação do menor desvalido, inserida na lógica do modelo filantrópico, visando o saneamento moral da sociedade a incidir sobre os pobres considerados delinquentes, desocupados, vadios2.

Entende-se que a primeira república foi um período de grandes avanços no âmbito educacional, quanto à criação de políticas públicas a partir da década de 1920 e de instituições de recolhimento de menores delinquentes. Entretanto, muitas instituições educativas de acolhimento de crianças e jovens pobres e desvalidos já existiam. O papel dessas instituições era o de lhes propiciar educação profissional e primeiras letras, como a Casa de Educandos Artífices no Pará, criada por José Antônio de Miranda (CASTRO, 2015).

Havia também a Companhia de Aprendizes Marinheiros, estabelecimento de regime militar que dava instrução elementar e disciplinar aos menores (CASTRO, 2013). Contudo, a Marinha se reorganizou conforme as transformações sociais, econômicas e políticas do período e as necessidades de composição das guarnições brasileiras, recorrendo ao recrutamento voluntário e à convocação de

\footnotetext{
2 “A repressão aos vadios no Brasil tem uma longa história. As Ordenações do Reino, que vigoraram por todo o período colonial, determinavam que os vadios, aqueles que não tinham senhores ou meios de ganhar a vida, fossem presos e açoitados. A mesma legislação previa que vadios detidos em Portugal poderiam ser mandados para o Brasil" (MELLO \& SOUZA, 1982 apud TEIXEIRA; SALLA; MARINHO, 2016, p. 384). "Entretanto, na tradição ibérica, e por consequência na formação social brasileira, jamais se desenvolveram as práticas comuns nos países do norte da Europa, as chamadas workhouses que confinavam os vadios, assim como os pequenos criminosos e todos aqueles [...] sem ocupação certa" (MELOSSI \& PAVARINI, 1985 apud TEIXEIRA SALLA; MARINHO, 2016, p. 384). "Tais instituições se organizavam pela imposição das práticas de trabalho e disciplina, premissas associadas ao mundo protestante emergente e a um ethos que no Brasil só tomaria corpo efetivo no final do Império e começo da República. Assim, no Império, mendigos, vagabundos e ébrios eram frequentemente obrigados a assinar o termo de bem viver imposto pela autoridade policial. Obrigava-se o indivíduo a viver 'decentemente', ordenamento que embutia um objetivo corretivo, pois previa o confinamento para aqueles que rompessem com o termo" (TEIXEIRA SALLA; MARINHO, 2016, p. 384).
} 
homens e crianças pobres, desvalidos e criminosos para aprender um ofício e servir à Pátria.

O discurso de juristas e filantropos determinou o encaminhamento de menores delinquentes às referidas instituições, segundo o Código Penal de 1890 (BRASIL, 1890), desvelando o desejo da elite e dos reformadores sociais de mantê-los fora das ruas(CORRÊA, 2017). Desse modo, surgiu a aliança entre justiça e assistência, que visou organizar a justiça pública e a assistência privada, proporcionando a esses menores um tratamento mais humanitário no processo de sentença e encaminhamento judicial (RIZZINI, 2011).

Diante do exposto, investiga-se o papel das Instituições Educativas no processo de regeneração social de crianças e adolescentes, pobres e criminosos, na capital do Pará, no período republicano. E sua importância no sentido de diminuir os altos índices de criminalidade infanto-juvenil, retirando os menores das ruas e dando-lhes uma ocupação. Para tanto, utilizou-se um recorte dos dados da dissertação intitulada "A Infância em Processos Judiciais em Belém do Pará: da criminalidade aos discursos jurídico-assistencialistas para a educação do menor desvalido (1890-1930)" (CORRÊA, 2017), onde foi possível identificar: a constituição da infância brasileira; a relação da infância paraense com a criminalidade; e as práticas educativas desenvolvidas pelas referidas instituições. O resultado da pesquisa demonstra um viés da sistematização ideológica do pensamento republicano paraense sobre a proposta educacional oferecida aos menores delinquentes, em acordo com o código penal de 1890.

\section{INFÂNCIA, CRIMINALIDADE E EDUCAÇÃO NO BRASIL (1890-1910)}

A infância é um período da vida que demanda atenção e cuidados, mas, por muito tempo, a criança brasileira enfrentou as

@rquivo Brasileiro de Educação, Belo Horizonte, v. 6, n. 14, mai-ago, 2018. 
mazelas sociais. O que se sabe sobre a infância no país está registrado em livros que descrevem a realidade de uma classe social abastada, onde o modelo de criança era um sujeito feliz e protegido pela família, autoridades e sociedade. Por outro lado, existia uma infância infortunada, sem voz e tratada com descaso, violência, abandono e trabalho. Sua imagem quase sempre se associava às páginas policiais ou a revistas de teor preventivo (CORRÊA, 2017).

$\mathrm{Na}$ antiguidade, as crianças eram tidas como seres inferiores que não mereciam tratamento especial, sendo, inclusive, a duração da infância reduzida. Tampouco acontecia com a infância desvalida no período em foco. Contudo, algum sentimento sobre infância existiu nas camadas mais nobres da sociedade, onde era possível reconhecer atitudes pertinentes a essa fase da vida. E mesmo para a infância amparada pela sociedade europeia, a de classes burguesas, existiu pouco ou nenhum sentimento fraternal, de proteção, de direitos e deveres para com a criança, até o século XII (ARIÈS, 1978 apud CORRÊA, 2017, p. 40).

Segundo Ariès (1978), a arte medieval ou desconhecia a infância, ou não tentava representá-la. É provável que essa ausência se devesse à falta de carinho, habilidade ou competência dos adultos. É uma ideia de sentimento deformado imposta por artistas medievais, ao destacar, por exemplo, os corpos, trajes e posturas de crianças em telas, diferentemente dos nossos sentimentos e atual visão de infância. Ariès (2015) afirma que, assim que a criança deixava os cueiros, era vestida e ensinada conforme as regras de comportamento dos homens e mulheres de sua condição.

No processo de colonização do Brasil, as crianças estiveram presentes nas embarcações que trouxeram de Portugal aqueles que se aventuraram às terras de Santa Cruz. Crianças desvalidas só subiam nas embarcações na condição de "pajens" ou "grumetes" e como órfãs do 
Rei (meninas enviadas à colônia para se casar com súditos da Coroa Portuguesa). Nesse período, as crianças pobres foram submetidas a diferentes maus tratos, como violência, enfermidades diversas e sobrecarga de trabalho, incluindo abusos sexuais por parte de marujos rudes e pedófilos (RAMOS, 1999).

As crianças da colônia, tanto imigrantes vindas de Portugal quanto as nativas, sofreram as agruras da colonização. A epopéia marítima trouxe, também, os padres jesuítas da Companhia de Jesus, ordem religiosa cuja preocupação era catequizar os nativos, principalmente, filhos dos índios, na chamada "conversão dos gentios",encarregando-se de ensinar aos meninos como ler e escrever,a fim de doutriná-los e torná-los subservientes aos colonizadores (SABINO, 2012).

Outro elemento a ser reportado é a escravidão negra de crianças, aviltadas por sua condição desde a colônia. Faleiros (1995) aponta que a baixa taxa de crescimento populacional dos escravos se deu por diversos fatores, como os abortos por maus-tratos, a mortalidade infantil em virtude das péssimas condições dos cativeiros e os infanticídios praticados pelas mães como forma de livrar seus filhos da escravidão. Com isso, tão logo as crianças eram submetidas ao trabalho.

De acordo com Mauad (2000), no período imperial, começou a se vislumbrar uma clara distinção entre o tratamento que se dava a meninos e meninas de classes abastadas e pobres. No universo feminino, eram valorizados os atributos manuais, e, no masculino, os intelectuais, neste havendo a opção pela formação militar. Os termos "menino e menina" já aparecem no dicionário no início do século XIX. Ésomente a partir de 1830 que o termo "criança" passou a ser utilizado nos dicionários com uso reservado para a espécie humana. Aponta-se, portanto, que a relação entre infância e puerícia se estabeleceu pelos

@rquivo Brasileiro de Educação, Belo Horizonte, v. 6, n. 14, mai-ago, 2018. 
atributos da fala, dentição, estado físico e tamanho da criança (MAUAD, 2000 apud SABINO, 2012).

Sabino (2012) ressalta, ainda, que os meninos da elite cursavam a escola aos sete anos de idade e terminavam seus estudos dentro ou até fora do Brasil, enquanto que, para as meninas da mesma classe, mantinha-se $O$ aperfeiçoamento das habilidades manuais e a valorização dos dotes sociais. Esse foi um dos fatores mais marcantes na definição dos papéis sociais do homem de elite, que deveria desenvolver uma postura viril e poderosa, isto é, uma plena capacidade intelectual; e da mulher, preparada apenas para $\circ$ universo doméstico e da maternidade.

A partir da segunda metade do século XIX, a emergência das atenções recaiu sobre a infância pobre e delinquente no Brasil, marcado por uma conjuntura de profundas transformações socioeconômicas e culturais, causadas, principalmente, pelo processo de extinção gradual da escravidão. A princípio, representado pela cessação do tráfico de escravos, com a promulgação, em 1850, da Lei Euzébio de Queiroz3; e, posteriormente, em 1871, pela Lei do Ventre Livre $^{4}$ e pela consequente substituição da mão-de-obra escrava pela livre (SABINO, 2012).

Sabino (2012) enfatiza que, a partir das análises atemorizantes sobre a infância desvalida da sociedade, começou a se desenhar um quadro preocupante para as autoridades, com efeitos a começar pelo fim da escravidão, crescimento e visibilidade do mercado de trabalho livre e, principalmente, pelo medo da "cidade negra, rebelde e

\footnotetext{
3 "Legislação que proibiu definitivamente o tráfico de escravos para o Brasil [...] Aprovada em 4 de setembro de 1850, apesar de não ter sido a primeira a proibir o tráfico de africanos para o país, foi a primeira a surtir impacto relevante sobre a escravidão" (SANTOS, 2009 apud CORRÊA, 2017, p. 46).

4 "[...] declarava livres os filhos de mulheres escravas nascidos após [1850]. Estipulava obrigações para os senhores de escravos e para o governo, proibindo a separação dos filhos menores de 12 anos do pai ou da mãe. [...] tinha como preocupação o futuro dos descendentes de escravos, tônica dos debates públicos da época. Obrigava os senhores a criarem os filhos das escravas até a idade de 8 anos, após este período, poderiam receber uma indenização do Estado ou serem usados como trabalhadores até à idade de 21 anos" (PAVÃO, 2011, p. 7).
}

@rquivo Brasileiro de Educação, Belo Horizonte, v. 6, n. 14, mai-ago, 2018. 
doente". Esse panorama esboçado pelas teses jurídicas assustava a elite contemporânea, que olhava a multidão e o crescimento urbano como "eminentes propagadores da desordem".Foi preciso, então, assistir à infância,o que passou a ser dever do Estado (CORRÊA, 2017, p. 47).

Após 1871, descendentes de escravos libertos, menores, em geral, imigrantes e mestiços, se tornaram objeto da elite pensante no Brasil. Nesse período, os discursos de homens públicos, reformadores e filantropos propunham a "fundação de escolas públicas, asilos creches, escolas industriais e agrícolas de cunho profissionalizante, além de uma legislação para menores" (ABREU; MARTINEZ, 1997, p. 25). Buscava-se inserir nas práticas jurídico-policiais o encaminhamento para Casas de Educação, Educandários, Institutos Orfanológicos e Reformatórios "para os chamados menores abandonados e delinquentes" (ABREU; MARTINEZ, 1997, p. 25).

A partir da Primeira República, a criança pobre passa a se destacar na sociedade brasileira como magno problema social. Nesse sentido, Rizzini (2004, p. 12) comenta:

[...] na segunda metade do século XIX, no Brasil, surgiram as primeiras medidas efetivas dos poderes públicos com relação à infância pobre, destinada a proteção dos "Meninos Desvalidos", que nesse momento histórico significava dizer "aquele que não tem valor, sem valimento" e "sem valia", encontra-se desprotegido, desamparado, desgraçado, miserável.

Desse modo, a origem de tal "desorganização social" desembocou na criminalidade infantil, fruto da industrialização e urbanização no país. É a partir desse cenário que surge uma nova perspectiva de infância no Brasil (CORRÊA, ALVES, OLIVEIRA; SILVA, 2015). Segundo Rizzini e Pilotti (201 1, p. 23-24),

Em meados do século XIX, houve grande demanda da força de trabalho nas fábricas, sobretudo, as de tecido. Crianças 
foram incorporadas, recebendo salários baixos, e recrutadas de asilos, cumprindo carga horária semelhante a dos adultos5. Esses menores trabalhavam para contribuir na renda mensal familiar. Os patrões alegavam que a exploração infantil retirava os menores da ociosidade e das ruas, dando-lhes uma ocupação útil.

Observa-se que, no fim do século XIX, as políticas públicas voltadas para a infância brasileira começaram a ser pensadas. As iniciativas nesse sentido estavam ligadas apenas às ações de cunho caritativo-religioso, evidenciando que a responsabilidade para com a infância se dava apenas no âmbito privado. A sociedade estava mais preocupada com as ameaças que lhe tiravam a paz do que com o futuro daqueles pequenos cidadãos, entregues a toda "sorte" de vícios (CORRÊA, 2017, p. 48). É nessa profusão de acontecimentos que, de fato, as políticas educacionais de democratização do ensino começam a caminhar, a passos lentos, e que a criança começa a ser pensada como sujeito com deveres e direitos na sociedade brasileira (CORREAA, 2017). As estratégias político-sociais começaram a se desenhar no cenário nacional e, pouco a pouco, o atendimento à infância pobre ganhou força nos âmbitos jurídico e social.

\section{O ENCAMINHAMENTO DE MENORES DELINQUENTES ÀS INSTITUIÇÕES EDUCATIVAS NA BELÉM REPUBLICANA}

A criminalidade infantil é uma realidade contemporânea, com origem, no Brasil, a partir do século XIX, afetando, principalmente, a infância desvalida. Estudos realizados por Santos (1999) e Rizzini (2011) apontam que essa questão foi se agravando no decorrer do tempo, e que a realidade das crianças pobres envolvidas com a criminalidade se tornou uma situação preocupante no país. No início da República,

\footnotetext{
5 “A estratégia de encaminhamento da criança pobre para o trabalho articula o econômico com o político, referindo-se ao processo de valorização/desvalorização da criança enquanto mão-de-obra, como se a desigualdade social fosse natural. Nessa ótica, aos pobres dominados caberia trabalhar, aos ricos e dominantes caberia dirigir a sociedade" (FALEIROS, 2011, p. 34).
}

@rquivo Brasileiro de Educação, Belo Horizonte, v. 6, n. 14, mai-ago, 2018. 
"recorrentes práticas de pequenos furtos envolvendo crianças marcaram esse período, o que ocasionou um problema de ordem social" (CORRÊA, 2017, p. 59).

Não obstante, as mazelas sociais da infância brasileira na contemporaneidade nada mais são do que uma correspondência de sua constituição no passado. Por longo período, as crianças vivenciaram agruras no campo jurídico e social, que trazem à baila uma discussão acerca do seu desenvolvimento enquanto sujeitos de direitos e deveres. No século XXI, emerge um avanço significativo no corpo de leis que representam a infância brasileira quanto à sua seguridade social. Hoje, o que mais se evidencia nos debates sociais, em congressos e seminários acadêmicos sobre infância. É a assistência à criança pobre, em situação de risco, destacando os seus direitos, pautados na Constituição Federal (1988), Lei de Diretrizes e Bases da Educação (Lei $n^{\circ}$ 9.394/1996) e Estatuto da Criança e do Adolescente (Lei n 8.069/1990). Ressalta-se também, os crescentes índices de violência doméstica, abusos sexuais e criminalidade infantil no país, onde Belém do Pará aparece em notícias midiáticas como uma das capitais mais violentas, com altos índices de criminalidade infanto-juvenil.

Monteiro e Alves (2012) apontam diversas causas interrelacionadas para o envolvimento de crianças e adolescentes com a criminalidade em Belém, como abandono escolar, envolvimento com drogas, desestruturação familiar e, principalmente, falta de perspectiva de vida. Do estudo realizado pelas autoras, observou-se que 18 adolescentes investigados, que cumpriam medidas socioeducativas na unidade de Val-de-Cães, envolveram-se muito cedo com a criminalidade.

Pesquisas apontam que a criminalidade infanto-juvenil no Brasil se agrava desde o período republicano, e que a realidade de menores envolvidos com a marginalidade é uma situação recorrente (CORRÊA,

@rquivo Brasileiro de Educação, Belo Horizonte, v. 6, n. 14, mai-ago, 2018. 
ALVES, OLIVEIRA; SILVA 2015). A Belém da primeira república vivenciou uma situação semelhante às demais capitais, com o crescimento do movimento da Belle Époque e as transformações políticas, econômicas e sociais decorrentes do projeto de modernização da cidade e comercialização da borracha. Segundo Alves (2012), nos finais do século XIX, a cidade recebeu pessoas de vários lugares do país e do exterior, que chegavam à Amazônia, motivadas pela economia da borracha, em busca de acolhimento, sem temer. Contudo, as dificuldades que encontrariam à frente. Tal acontecimento obrigou o poder público a tomar diferentes medidas para garantir a ordenação da cidade e atender a uma elite moderna, formada pelos barões da borracha (CORRÊA, 2017, p. 140).

Nesse cenário, o projeto de modernização de Belém, de um lado, contribuiu para o crescimento socioeconômico da capital, formando uma nova sociedade; de outro, a pobreza e o descaso eram evidentes. Compreende-se que, no fim do século XIX e início do século XX, Belém cresceu demograficamente de forma acelerada, e normas foram estabelecidas para que nada interferisse no projeto de "cidade modelo" (CORRÊA, 2017, p. 141). Um dos princípios desse projeto foi manter a ordem pública por meio da contenção do grande número de crianças nas ruas. Corrêa Alves, Oliveira; Silva(2015) apontam que as práticas delituosas de menores aceleraram, acompanhando 0 desenvolvimento urbano, econômico e social da cidade. Nesse contexto, as ruas não eram vistas como lugares apropriados para transeuntes como mulheres e crianças, e todo menor que ali fosse encontrado devia se justificar e/ou provar sua situação. Assim, a vadiagem/vagabundagem/desordem, tornaram-se práticas consideradas delituosas naquela época (CORRÊA, 2017, p. 142).

O ideário republicano no Brasil consubstanciou algumas estratégias, pensadas e articuladas pelas autoridades e elite, que 
uniram forças no âmbito assistencialista com outras instituições (religiosas e sociais), "no sentido de 'proteger' a criança desvalida e a sociedade dos perigos urbanos, retirando-as das ruas, e encaminhandoas para um ofício; criando políticas de ordenamento, saneamento e disciplinamento da infância marginalizada de acordo com o código penal de 1890" (CORRÊA, 2017, p. 82).

Não obstante, Safelice (2007, p. 77) destaca que, quando se estuda a história das instituições educativas, o condicionante inicialmente posto é o da temporalidade. Desse modo, entende-se que investigar o papel das instituições educativas no encaminhamento de menores delinquentes na cidade de Belém no período republicano é se aprofundar em sua história como objeto de análise. No interior dessas instituições há um "quebra-cabeça" a ser decifrado, pois, se o caminho para adentrar uma instituição perpassa o campo material (alicerces, porões, sótãos, telhados, chaminés, objetos, cadeiras, mesas, quadros negros etc.), o desafio é entrar na instituição.

Trata-sede organizar as peças para montar o quebra-cabeça: legislação, padrões disciplinares, conteúdos escolares, relações de poder, ordenamento do cotidiano, uso dos espaços, de objetos pedagógicos, docentes, alunos e outras coisas que ali cruzam. Pode-se dizer que as instituições educativas ou escolares são a síntese de múltiplas determinações, de variadas instâncias (política, econômica, cultural, religiosa, da educação geral, moral, ideológica etc.) que "agem e interagem entre si, acomodando-se dialeticamente de maneira que resulte em uma identidade" (SAFELICE, 2007, p. 76).

Nesse sentido, Oliveira (2012) revela que os modelos de educação escolar aplicados nas instituições educativas nos finais do século XIX e início do século XX estavam diretamente ligados aos ideários civilizatórios iluministas, segundo os quais, para que houvesse progresso, era preciso ordenar e adestrar a população dita perigosa.

@rquivo Brasileiro de Educação, Belo Horizonte, v. 6, n. 14, mai-ago, 2018. 
Inventar o Brasil "a partir do ideário iluminista foi um processo que perdurou até $O$ final do regime imperial e trouxe significativas modificações nos diferentes mecanismos educacionais, particularmente nos debates pedagógicos" (CORRÊA, 2017, p. 82).Enfatiza-seque a pedagogia participou desse jogo de saber-poder, bem como foi utilizada como agente normalizador dos corpos desses "deseducados" nos espaços intramuros da prisão (FOUCAULT, 1982).

Sobre essa análise, Foucault (2005) problematiza sobre "Iugares de sequestro", fazendo referência a prisões, escolas, manicômios e hospitais, tentando demonstrar como esses locais colaboram para educar, adestrar os corpos desses sujeitos, via vigilância e punição. A vigilância hierárquica e a sanção normalizadora, combinadas com um procedimento de exame, formam instrumentos aos quais se deve o sucesso do poder disciplinar. O exame exerce "[...] uma vigilância que permite qualificar, classificar e punir [...]" (FOUCAULT, 2005, p.154), "estabelecendo, nesse sentido, uma visibilidade constante sobre os indivíduos fazendo com que sejam diferenciados e sancionados".

A partir desse panorama sócio-histórico do país e as ações jurídicas no sentido de recolher crianças sem comprovação de ofício lícito nas ruas, encaminhando-as ou sendo imputadas, mediante sentença de juiz de direito, instituiu-se o trabalho forçado, ou seja, a "pedagogia do trabalho", pois conforme (CORRÊA, 2017, p. 83),

\begin{abstract}
A pena específica da vagabundagem é incontestavelmente o trabalho coato. E é a pena específica, porque realiza completamente as duas funções que the incumbem: tem eficácia intimidativa, porque o vagabundo prefere o trabalho à fome; tem o poder regenerativo, porque, submetido ao regime das colônias agrícolas ou das oficinas, os vagabundos corrigíveis aprendem a conhecer e a prezar as vantagens do trabalho, voluntariamente, aceitos (RELATÓRIO DE JUSTIÇA, 1905 apud SANTOS, 1999, p. 229).
\end{abstract}

Nessa ótica, crianças e adolescentes envolvidos com a criminalidade foram encaminhados por chefes de polícia a instituições 
que acolhiam menores em todo o país. Em um momento crucial em que a sociedade trazia consigo a palavra dos representantes do Estado, que viam na educação para a infância o suporte para 0 "progresso" e modelo de "civilização" desejado (CORRÊA, 2017, p. 83). Não obstante, Barbosa (2012) pontua ainda que no período oitocentista, a melhoria da infraestrutura urbana na capital da Província do Grão Pará deu a Belém um ar mais civilizado. O crescimento, a reestruturação urbana, com o financiamento dos lucros do Ciclo Gomífero, e o projeto de modernização da cidade deram uma nova face à urbe, exigindo que todos soubessem como conviver nos novos espaços sociais e suscitando uma grande preocupação civilizatória. Para muitos intelectuais, juristas e políticos da época, os mais pobres, em sua maioria, miscigenados, eram considerados primitivos (índio e negro), e precisavam ser urgentemente morigerados. O autor aborda a situação da população pobre da capital paraense nesse período como inferior e predisposta aos vícios e desvios de caráter, já que viviam em estado de barbárie (CORRÊA, 2017, p. 24-25).

Barbosa (2012) afirma, ainda, que havia a preocupação por parte das autoridades, inclusive, identificada na leitura de jornais da época; que destacavam as crianças pobres como uma ameaça à sociedade, por descenderem de "raças inferiores", bem como por serem iniciadas precocemente nas ruas, no trabalho e em ambientes insalubres, considerados nocivos à ordem pública. Eram vistas como ameaça à paz e segurança da elite, pois o objetivo do projeto de modernização foi o de transformar Belém em uma Paris n'América, em cuidados com limpeza e estética da cidade, conforme a ordem republicana (CORRÊA, 2017, p 25).

Por conseguinte, em 1840, José Antônio de Miranda, através da Lei $n^{\circ} 79$, de 21 de outubro de 1840, autorizou a compra da casa e do terreno onde existia a Companhia de Educandos ou de obreiros, e lá

@rquivo Brasileiro de Educação, Belo Horizonte, v. 6, n. 14, mai-ago, 2018. 
instalou a Casa de Educandos Paraense. José Antônio de Miranda foi, para as províncias do Pará e do Maranhão, "o grande protetor de meninos e meninas pobres e desvalidos, ao recolhê-los em estabelecimentos e dar-lhes uma educação profissional e de primeiras letras" (CASTRO, 2015, p. 18).

Segundo Castro (2015), o Decreto $n^{\circ} 88$, de 24 de maio de 1841, que regulava a vida cotidiana dentro da instituição, dizia que os rapazes pobres, ali inseridos para o aprendizado de um ofício, eram destinados a combater: "os germens infalíveis da sua prosperidade, não aderindo à ociosidade e assumindo a condição de oficiais das artes fabris e mecânicas, com o rigor dos rudimentos indispensáveis para a cultura da razão" (Discurso recitado pelo Exm. Snr. Doutor José Antônio de Miranda, 1840, p. 15). Assim, o governo paraense deu à sociedade a esperança de ter "no seio dela, depois de três ou quatro anos", jovens capazes de sobreviver pelos "seus jornais". A Casa dos Educandos Artífices Paraense, em 1840, tinha o seu quadro de funcionários composto por um pedagogo, função exercida pelo capitão Joaquim Belfort Gomes; um médico de partido e um capelão, que eram responsáveis pelos educandos empregados nos ofícios apresentados. "Em 1844, começou a receber os expostos com a idade mínima de sete anos, como determinava o código de postura da cidade" (CASTRO, 2015, p. 19-20).

Mais tarde, a Casa passou por instabilidades financeiras e crises constantes, devido ao estado físico do prédio e à distância que dificultava o acesso dos educandos a oficinas particulares nas obras públicas da cidade. Após 1848, os educandos já estavam ociosos, e o estabelecimento se encontrava sem ferramentas e utensílios de trabalho, sem livros de registro, em um quadro de completo abandono, fechando as portas em 1855, porém retornando às suas atividades de recolhimento e ensino profissional de meninos pobres e desvalidos no

@rquivo Brasileiro de Educação, Belo Horizonte, v. 6, n. 14, mai-ago, 2018. 
ano de 1860 (CASTRO, 2015).

Nos institutos, o regime interno era rígido, exigindo-se cotidianamente dos menores, esforço e disciplina, para aprender os ofícios ensinados e bom desempenho, pois disso dependia sua permanência, com alguns benefícios e sem maiores punições. Havia duas formas de ingresso nesses estabelecimentos: encaminhamento pelas famílias, que pagavam para que seus filhos aprendessem um ofício e se mantivessem ocupados, fora das ruas; e o encaminhamento por sentença judicial. "Os menores considerados criminosos eram enviados de acordo com o crime cometido e com as penalidades aplicadas, permanecendo pelo tempo determinado pelo juiz de direito" (CORRÊA, 2017, p. 84).

Dentro da categoria de criminosos, duas seções foram criadas com o objetivo de corrigir os menores. Na primeira, estavam os que obraram com discernimento (conforme exposto no art. 30 do Código Penal Republicano de 1890), por crimes de diversas tipologias; na segunda, os que foram sentenciados sem comprovação no que está disposto no art. 30, isto é, mendigos, vadios, viciosos e abandonados, entre nove e quatorze anos, que não obraram com discernimento, "mediante ordem do chefe de polícia ou autoridade policial competente, após inquérito com testemunhas" (SANTOS, 1999, p. 225).

Segundo Santos (1999), o programa dos institutos compreendia: o ensino da leitura; princípios de gramática; escrita, caligrafia e cálculo aritmético; frações e sistema métrico; rudimentos de ciências físicas, químicas e naturais (aplicadas à agricultura); moral prática e cívica. Não compreendendo, portanto, o ensino religioso, mantendo o princípio do caráter laico do Estado republicano, de forma que os jovens eram livres para professar sua fé e religiões de origem. No mais, no que diz respeito à educação, os institutos muito deixavam a desejar de seu projeto inicial, pois eram frequentes os casos de jovens que, após

@rquivo Brasileiro de Educação, Belo Horizonte, v. 6, n. 14, mai-ago, 2018. 
longa estadia, dos institutos saíam sem nada aprender, em estado de semianalfabetismo (SANTOS, 1999, p. 225).

No caso das Companhias Militares da Marinha, enfatiza-se que nasceram, historicamente, para proteger a Marinha do Comércio num momento de desenfreada ambição, ânsia de domínio e consequente expansão geográfica, tão logo se constituindo num instrumento de ataque e de defesa das nações. "Foi com a vinda da família real para - Brasil em 1808 que se instalou aqui a Marinha Portuguesa e com a independência do país, surgiu a Marinha Brasileira" (CASTRO, 2013, p. 26).

Vale (2002) destaca que, com a concentração das forças militares da Corte nas províncias, a recém-nascida Marinha do Brasil enfrentou problemas de diversas ordens (necessidade de aparelhamento das armas nacionais, deficiência de material flutuante, mão-de-obra e dificuldades financeiras), o que obrigou D. João VI a procurar ajuda em seu país de origem. Contudo, com a independência, houve uma ruptura no quadro do pessoal da Marinha: uns regressaram a Portugal e outros permaneceram no Brasil. Diante desse cenário e, sobretudo, das condições do marujo nacional - caboclos pobres e ignorantes; trazidos à força do interior para servir em navios, porém, sem maiores ambições-, a marinha utilizou duas estratégias para compor as guarnições: o alistamento voluntário e o recrutamento forçado (CORRÊA, 2017, p. 85-86 apud VALE, 2002).

Os menores desvalidos ou sentenciados eram conduzidos às Companhias de Aprendizes Marinheiros, Artífices ou Arsenais de Marinha, por meio dos chefes de polícia e juízes de órfãos, para serem aquartelados (CORRÊA, 2017, p. 86). Araújo (2014) menciona outras formas de recrutamento: os que não eram órfãos ou desvalidos e cujos tutores solicitavam que fossem alistados, casos de pessoas que não possuíam vínculo nenhum com os menores, mas, os deixavam lá

@rquivo Brasileiro de Educação, Belo Horizonte, v. 6, n. 14, mai-ago, 2018. 
mediante pagamento; ou pela livre iniciativa dos menores, como voluntários que desejavam fazer parte da Companhia. Mas, considerando-se que o número de voluntários para o recrutamento era insignificante, o recrutamento forçado passou a ser a única forma eficaz para a Armada.

Maia (1965, p. 227) esboça uma noção do público-alvo, das formas de recrutamento e da instrução oferecida nas Companhias Fixas de Marinheiros:

Começou por engajar jovens de 12 a 16 anos, embarcando-os em navios [...] a bordo dos quais, criaram-se para eles escolas de inserção de instrução primária, ao mesmo tempo, que faziam a aprendizagem da arte do marinheiro. [...] o maior número de aliciados foi de menores órfãos e desvalidos e rapazes de 14 a 17 anos, apreendidos por não terem ofício ou ocupação útil.

As Companhias Militares eram regulamentadas pelas disposições do Decreto $n^{\circ} 1.517$, de 4 de janeiro de 1855, que definia o seu públicoalvo, as condições de acesso, educação oferecida, permanência, entre outros:

Art. 8. Para ser admitido como aprendiz marinheiro era necessário: "ser cidadão brasileiro, ter idade entre 10 a 17 anos, ser de constituição robusta e própria para a vida no mar";

Art. 9. Também poderiam ser admitidos menores de 10 anos de idade que apresentassem desenvolvimento físico suficiente para começar o aprendizado;

Art. 10 e 11. As vagas eram preenchidas por voluntários ou contratados a prêmio, matriculados por pais ou tutores; por órphãos e desvalidos, que possuindo os requisitos solicitados, fossem remetidos pelas autoridades competentes designadas pelo Presidente da Província: juízes de órphãos e autoridades policiais (CASTRO, 2013, p. 39-40).

$\mathrm{Na}$ instrução elementar, os menores aprendiam a riscar mapas, ler, escrever, contar e a doutrina Cristã, servindo-lhes de mestre o Capelão do Arsenal ou um oficial habilitado. A educação proposta evidenciava os interesses da Marinha na preparação de mão de obra para os seus serviços, pois se tratava de uma instituição destinada às 
crianças pobres; "àquelas que atendiam ao perfil desejado para o serviço da Armada, portanto, ser pobre, não era um critério que garantia o acesso a essa escola, mas o desenvolvimento físico" (CASTRO, 2013, p. 41).

Todavia, Araújo (2014) ressalta que se rejeitavam indivíduos com deficiência ou qualquer tipo de doença, porém, não eram descartados, mas enviados a outras oficinas de artífices dos Arsenais, servindo como artífices marinheiros. Outros fatores contribuíram para a diminuição do número de menores nas Companhias: entre os anos 1765 e 1870, o Arsenal de Marinha recebeu poucas crianças, pois seus pais temiam que fossem enviadas à guerra do Paraguai - o que certamente podia acontecer, uma vez que muitos menores foram utilizados na Armada durante o referido conflito (PINHEIRO, 2003).Entende-se, portanto, que o objetivo das Companhias não era para atender aos menores como instituições filantrópicas e mantidas pelo Estado, mas para recrutá-los segundo as exigências de uma sociedade elitista, cujas bases se sustentaram numa ideia individualista de progresso da nação, prevenção social e, sobretudo, para compor a mão-de-obra nas guarnições da Marinha.

Assim sendo, analisou-se o papel das instituições educativas no encaminhamento de menores considerados delinquentes na Belém republicana com a intenção de externar a visão de mundo que tinha essa sociedade. Ao orientar projetos para o engrandecimento da Pátria e modernização da capital paraense, utilizando a educação profissional como meio de salvá-los da corrupção das ruas e da criminalidade. Tais projetos orientavam concepções de ordem cultural, política, ética, teológica e estética, comprometidos "dialeticamente com a cultura a produzir-se e reproduzir-se entre os educandos" (ARAúJO, 2007, p. 96). Para Araújo (2007), não se pode afirmar que as instituições educativas são expressões particulares ou individualizadas,

@rquivo Brasileiro de Educação, Belo Horizonte, v. 6, n. 14, mai-ago, 2018. 
mas, coparticipantes de projetos em um dado momento histórico; vinculados a visões de mundo que se confrontam em dada conjuntura, fazendo valer dada concepção, numa estratégia pensada como influência, em vista do exercício de disputa e de hegemonia.

\section{CONCLUSÃO}

O fim do século XIX e início do século XX marcaram a história da infância e da educação brasileira pelas grandes transformações sociais, provocando repercussão nacional sobre a formação da sociedade. A explosão demográfica, a industrialização, a modernização da cidade de Belém, a criminalidade infantil em algumas capitais do Brasil e a criação de instituições educativas; foram iniciativas de organizações filantrópicas e condições mínimas do Estado para o engrandecimento do país, reforçando o objetivo de fazer a Pátria ganhar ares de nação civilizada e moderna, conforme os modelos internacionais, e de retirar os menores delinquentes das ruas, proporcionando-lhes um ofício.

A partir de tal realidade, a sociedade brasileira e autoridades voltaram suas atenções para a criança desvalida, sobretudo, após a imigração estrangeira e abolição da escravatura, possibilitando o crescimento do mercado de trabalho livre no país. Assim, começou a se vislumbrar medidas efetivas dos poderes públicos com relação à infância desvalida. O crescimento acelerado de menores ligados a crimes acompanhou a industrialização nas principais capitais brasileiras, resultando no aumento do número de cortiços, favelas, epidemias etc. Por um lado, a economia ostentava o luxo das elites, e, por outro, agravava cada vez mais a pobreza. O projeto de modernização de Belém não pormenorizou a condição de pobreza das massas, revolucionando o cotidiano da cidade e as relações interpessoais.

Os debates articulados com o pensamento republicano para $\circ$ 
progresso da nação estavam, na maior parte das cidades do país, em dissonância com o código penal republicano (1890), que estabeleceu mudanças quanto à maioridade penal e formas de punição de menores considerados delinquentes que "agiam com discernimento". Este pensamento também se fomentou na proposta patriótica de modernização nacional segundo modelos internacionais e, nesse rebojo, a sociedade paraense determinou regras de comportamento para o cidadão como meio de romper com a rudeza social. No caso da educação, utilizou-se a prática positivista do trabalho coato, pelo encaminhamento de menores a instituições como estratégia de regeneração social dos judicialmente sentenciados.

\section{REFERÊNCIAS}

ABREU, M., MARTINEZ, A. F. Olhares sobre a criança no Brasil: perspectivas históricas. In RIZZINI, Irene (org.), Olhares sobre a criança no Brasil: século XIX e XX. Rio de Janeiro, RJ: Amais, 1997. p. 19-38.

ALVES, Laura Maria Silva Araújo. (2012). Proteção e assistência à infância desvalida no Pará (1912-1934). In: SEMINÁRIO NACIONAL DE ESTUDOS E PESQUISAS "HISTÓRIA, SOCIEDADE E EDUCAÇÃO NO BRASIL", 9., 2012,Campinas, SP. Anais [...] Campinas, SP: HISTEDBR, 2012. p. 32953313.Disponível em:

http://www.histedbr.fe.unicamp.br/acer_histedbr/seminario/seminario9/ PDFs/4.22.pdf. Acesso em: 25 fev. 2018.

ARAÚJO, José Carlos Souza. As instituições escolares na Primeira República: ou os projetos educativos em busca de hegemonia. In: NASCIMENTO, Maria Isabel Moura, SANDANO, Wilson; LOMBARDI, José Claudinei; SAVIANI, Dermerval (org.). Instituições escolares no Brasil: conceito e reconstrução histórica.Campinas, SP: Autores Associados, 2007. p. 95-122.

ARAÚJO, Telmo Renato da Silva. Entre a criminalidade e o cotidiano militar: a inserção de menores nas Forças Armadas no Pará em finais do século XIX. Belém, PA: UEPA, 2014.

ARIÈS, Philippe. História social da criança e da família. Rio de Janeiro, RJ: 
Zahar, 1978.

ARIÈS, Philippe. História social da criança e da família. 2. ed. Rio de Janeiro, RJ: LTC, 2015.

BARBOSA, Anderson Carlos Elias. A formação de cidadãos "distinctos e morigerados" na Província do Grão-Pará (1870-1889). Revista Ver a Educação, v.12, n.2, p. 247-270, 2012.

CASTRO, C. A. A educação da infância desvalida paraense nos oitocentos: a casa de educandos artífices. In: ARAÚJO, Laura Silva Araújo Alves; FRANÇA, Maria do Socorro G.; ALVES, Avelino Silva Araújo (org.). Educação e instrução pública no Pará imperial e republicano. Belém, PA: Eduepa, 2015. p. 17-34.

CASTRO, Rozenilda. A escola de aprendizes marinheiros da Parnaíba. 2. ed. Teresina, PI: Edufpi, 2013.

BRASIL. Constituição (1988). Constituição da República Federativa do Brasil. Brasília: Senado, 1988. Disponível em:

http://www.planalto.gov.br/ccivil_03/constituicao/constituicaocompilad o.htm. Acesso em: 25 fev. 2018.

BRASIL. Decreto $n^{\circ} 1.517$, de 4 de Janeiro de 1855. Crêa huma Companhia de Aprendizes Marinheiros na Província do Pará, e manda observar o Regulamento respectivo. Diário Oficial da União, Brasília, 31 dez. 1855.

Disponível em: https://www.diariodasleis.com.br/legislacao/federal/196499crua-huma-companhia-de-aprendizes-marinheiros-na-provincia-do-paru-emanda-observar-o-regulamento-respectivo.html. Acesso em: 25 fev. 2019.

BRASIL. Decreto n 847, de 11 de outubro de 1890.

Promulga o Codigo Penal. CLBR, Brasília, 1890. Disponível em:

http://www.planalto.gov.br/ccivil_03/decreto/1851-

1899/D847.htmimpressao.htm. Acesso em: 25 fev. 2019.

BRASIL. Lei n 8.069, de 13 de julho de 1990. Dispõe sobre o Estatuto da Criança e do Adolescente e dá outras providências. Diário Oficial da União, Brasília, 16 jul. 1990. Disponível em:

http://wwww.planalto.gov.br/ccivil_03/leis/L8069.htm. Acesso em: 01 mar. 2019.

BRASIL. Lei n 9.394, de 20 de dezembro de 1996. Estabelece as diretrizes e bases da educação nacional. Diário Oficial da União, Brasília, 23 dez. 1996. Disponível em: http://www.planalto.gov.br/ccivil_03/leis/L9394.htm. Acesso em: 25 fev. 2019

@rquivo Brasileiro de Educação, Belo Horizonte, v. 6, n. 14, mai-ago, 2018. 
CORDEIRO, Sandro da Silva; COELHO, Maria das Graças Pinto.

Descortinando o conceito de infância na história: do passado à contemporaneidade. In: CONGRESSO LUSO-BRASILEIRO DE HISTÓRIA DA EDUCAÇÃO, 6., 2006, Uberlândia, MG. Anais [...]. Uberlândia, MG: Universidade Federal de Uberlândia, 2006. p. 882-889.

CORRÊA, Liliane da Silva França. A infância em processos judiciais em Belém do Pará: da criminalidade aos discursos jurídico-assistencialistas para a educação do menor desvalido (1890-1930). 2017. 189f.

Dissertação (Mestrado) - Programa de Pós-Graduação em Educação, Universidade Federal do Pará, Belém, PA. Disponível em:

http://repositorio.ufpa.br/jspui/handle/2011/8691. Acesso em: 25 fev. 2019.

CORRÊA, L. S. F., ALVES, L. M. S. A., OLIVEIRA, C. V. C. P., SILVA, M. O. A. A infância em processos judiciais: um estudo discursivo sobre o caso do menor Joaquim Manoel da Silva em Belém do Pará de 1895. In COLÓQUIO DE PESQUISA DA LINHA EDUCAÇÃO, CULTURA E SOCIEDADE: A PRODUÇÃO DO CONHECIMENTO EM EDUCAÇÃO NA AMAZÔNIA, 3., 2015. Belém, PA. Anais [...]Belém, PA: Universidade Federal do Pará. p. 112

FALEIROS, E. S. A criança e o adolescente: objetos sem valor no Brasil Colônia e no Império. In: PILOTTI, Francisco;RIZZINI, Irene (org.).A arte de governar crianças: a história das políticas sociais, da legislação e da assistência à infância no Brasil Rio de Janeiro: Instituto Interamericano del Niño, 1995. p. 221-236.

FALEIROS, V. P. Infância e o processo político no Brasil. In: PILOTTI, Francisco; RIZZINI, Irene (org.). A arte de governar crianças. São Paulo, SP: Cortez, 2011 . p. 33-96.

FOUCAULT, Michel. Vigiar e punir: nascimento da prisão. 30. ed. Petrópolis, RJ: Vozes, 2005.

FOUCAULT, Michel. Microfisica do poder. 3 ed. Rio de Janeiro. Editora: Graal, 1982.

FOUCAULT, Michel. Vigiar e punir: nascimento da prisão. Tradução de Raquel Ramallete. 30 ed. Petrópolis: Vozes p. 288, 2005.

MAIA, Prado. A Marinha de Guerra do Brasil na colônia e no império: tentativa de reconstituição histórica. Rio de Janeiro, RJ: Livraria José Olympio, 1965.

@rquivo Brasileiro de Educação, Belo Horizonte, v. 6, n. 14, mai-ago, 2018. 
MAUAD, A. M. A vida das crianças de elite durante o Império. In:

MONTEIRO, Regina Fernandes; ALVES, Laura Maria Silva Araújo.Memórias de escola de adolescentes em conflito com a lei: violência,

criminalidade e educação. Belém, PA: Gutemberg, 2012.

MONTENEGRO, W. (2010). Antonio Lemos deu um passo ao futuro. In Faculdade de

História. Acessado em: http://www.ufpa.br/historia/index.php?option=c om_content\&view=article\&id=30:antonio-lemos-deu-um-passo-ao-futuro

PRIORE, Mary Del (Org.). História das crianças no Brasil. São Paulo, SP: Contexto, 2000. p. 137-176.

OLIVEIRA, Jailton Alves. Livros de matrículas da casa de detenção: memórias dos "deseducados" da Côrte (1880-1889). Revista História, v. 3, n.1, p. 52-73, 2012.

PAVÃO, Eduardo Nunes Alvares. Balanço histórico e historiográfico da assistência à infância "desvalida" no brasil. In SIMPÓSIO NACIONAL DE HISTÓRIA, 26., 2011 ,São Paulo, SP. Anais [...] São Paulo, SP: ANPUH, 2011. p. 1-18.

PINHEIRO, Luciana de Araújo. A civilização do Brasil através da infância: propostas e ações voltadas às crianças pobres nos anos finais do Império(1879-1889). 2003. 144f. Dissertação(Mestrado) - Programa de Pós-Graduação em História, Universidade Federal Fluminense, Niterói, RJ, 2003.

RAMOS, Fabio Pestana. A história trágico-marítima das crianças nas embarcações portuguesas do século XVI. In: PRIORE, Mary del (org.).História das crianças no Brasil.São Paulo, SP: Contexto, 1999. p. 2049.

RIZZINI, Irma. O cidadão polido e o selvagem bruto: a educação dos meninos desvalidos na Amazônia Imperial. 2004. 430f. Tese (Doutorado) - Programa de Pós-Graduação em História Social, Universidade Federal do Rio de Janeiro, Rio de Janeiro, RJ, 2004.

RIZZINI, Irma. O século perdido: raízes históricas das políticas públicas para infância no Brasil. 3. ed. São Paulo, SP: Cortez, 2011.

RIZZINI, Irma; PILOTTI, Francisco (org.). A arte de governar crianças: a história das políticas sociais, da legislação e da assistência à infância no Brasil.3. ed. São Paulo, SP: Cortez, 2011.

@rquivo Brasileiro de Educação, Belo Horizonte, v. 6, n. 14, mai-ago, 2018. 
SABINO, Elianne Barreto. A assistência e a educação de meninas desvalidas no Colégio Nossa Senhora do Amparo na província do GrãoPará(1860-1889). 2012. 157f. Dissertação (Mestrado) - Programa de PósGraduação em Educação, Universidade Federal do Pará, Belém, PA, 2012.

SAFELICE, José Luís. História das instituições escolares. In: NASCIMENTO, Maria Isabel Moura; SANDANO, Wilson, LOMBARDI, José Claudinei; SAVIANI, Dermeval (org.).Instituições escolares no Brasil: conceito e reconstrução histórica. Campinas, SP: Autores Associados, 2007. p. 75-93.

SANTOS, Marco Antônio Cabral dos. Criança e criminalidade no início do século. In: PRIORE, Mary del (org.). História das crianças no Brasil. São Paulo, SP: Contexto, 1999. p. 210-229.

TEIXEIRA, Alessandra; SALLA, Fernando Afonso; MARINHO, Maria Gabriela da Silva Martins da Cunha. Vadiagem e prisões correcionais em São Paulo: mecanismos de controle no firmamento da República. Estudos Históricos,v.29, n.58, p. 381-400, maio/ago. 2016.

VALE, B. A criação da marinha imperial. In: Brasil, Marinha, História Naval Brasileira - Rio de Janeiro, RJ: SDGM, 2002. p. 63-88. 